\title{
Ringing the Changes in Sport Nutrition and Exercise Metabolism
}

As we enter a new decade with our first issue of 2020, this short editorial serves to announce a number of important developments at International Journal of Sport Nutrition and Exercise Metabolism (IJSNEM). I should start by noting that you are not presently reading the words of Professor Ronald Maughan, who has now passed the torch after 10 years of successfully leading the journal as Editor-in-Chief. Over a gradual handover period, Professor Maughan and I have worked closely, along with Professor Louise Burke (Special Projects Editor), to develop a strategic plan that best serves the mission of this journal.

One development that readers may already have noticed on the masthead of IJSNEM is that we have recently refreshed the membership of our Editorial Board, including the addition of new Associate Editors (i.e., those who oversee peer review) to suit the growing number and changing nature of submissions received by the journal. I am also especially pleased to report that Professor Greg Atkinson has joined the journal in a newly created role of Statistical Editor.

Another major initiative that I am excited to share is our new submission checklist (Proper Reporting of Evidence in Sport \&
Exercise Nutrition Trials [PRESENT] 2020), which establishes standards to improve the reporting of exercise- and nutrition-related research. Contributors to the journal simply complete the checklist that is now integrated into our online submission process to identify the location of relevant information in their manuscript-this task can typically be completed within a matter of minutes, given that the majority of submissions already meet the required standards of reporting. Each item included in the PRESENT 2020 checklist is expanded upon in the associated paper published in this current issue of IJSNEM (https://doi.org/10.1123/IJSNEM.2019-0326), which we hope provides a useful educational resource not only to improve how science is reported in our field, but ultimately, to help advance the quality of that underlying science.

I look forward to working with contributors to IJSNEM during my time as Editor-in-Chief and am grateful for the continued support of all those driving progress within the fascinating and important branches of science represented by this journal.

Professor James A. Betts, PhD, FACSM, University of Bath, Bath, United Kingdom 